\title{
NEW POLYAMIDES BASED ON 1,3-BIS(4-CARBOXY PHENOXY) PROPANE AND HYDANTOIN DERIVATIVES: SYNTHESIS AND PROPERTIES
}

\author{
Khalil Faghihi $^{*}$ and Nasim Valikhani \\ Organic Polymer Chemistry Research Laboratory, Department of Chemistry, Faculty of Science, \\ Arak University, Arak, 38156, Iran
}

(Received April 24, 2009; revised August 10, 2009)

\begin{abstract}
Six new polyamides 5a-f containing flexible trimethylene segments in the main chain were synthesized through the direct polycondensation reaction of 1,3-bis(4-carboxy phenoxy) propane 3 with six derivatives of hydantoins $\mathbf{4 a - f}$ in a medium consisting of $\mathrm{N}$-methyl-2-pyrrolidone, triphenyl phosphite, calcium chloride and pyridine. The polycondensation reaction produced a series of novel polyamides in high yield with inherent viscosities between $0.30-0.47 \mathrm{dL} / \mathrm{g}$. The resulted polymers were fully characterized by means of FT-IR, ${ }^{1} \mathrm{H}-\mathrm{NMR}$ spectroscopy, elemental analyses, inherent viscosity, solubility tests and gel permeation chromatography (GPC). Thermal properties of these polymers were investigated by using thermal gravimetric analysis (TGA) and differential thermal gravimetry (DTG). The glass-transition temperatures of these polyamides were recorded between 130 and $155^{\circ} \mathrm{C}$ by differential scanning calorimetry (DSC), and the $5 \%$ weight loss temperatures were ranging from 325 to $415{ }^{\circ} \mathrm{C}$ under nitrogen. 1,3-bis(4-Carboxy phenoxy) propane $\mathbf{3}$ was prepared from the reaction of 4-hydroxy benzoic acid 1 with 1,3-dibromo propane 2 in the presence of $\mathrm{NaOH}$ solution.
\end{abstract}

KEY WORDS: Polyamides, 1,3-bis(4-Carboxy phenoxy) propane, Hydantoin derivatives, Inherent viscosity

\section{INTRODUCTION}

Aromatic polyamides have received considerable attention with regard to the production of high performance materials due to their outstanding thermal stability, chemical resistance and electrical and mechanical properties [1-3]. However, their applications are restricted because of their poor solubility in organic solvents and too high glass transition temperatures that make them very difficult to be processed by spin coating or thermoforming techniques [4-5]. Much effort has been made to create structurally modified aromatic polymers having increased solubility and processability with retention of their high thermal stability. It is known that the solubility of polymers is often increased when flexible bonds such as [-O-, $-\mathrm{SO}_{2}-,-\mathrm{CH}_{2^{-}}$, $\left.-\mathrm{C}\left(\mathrm{CF}_{3}\right)_{2}\right]$, bulky pendent groups (such as $t$-butyl, adamantyle and naphthyl), large pendent groups or polar constituents such as heterocyclic segments are incorporated into the polymer backbone due to the altering crystallinity and intermolecular interactions [6-8]. If the flexible segments are carefully chosen, it is possible to promote solubility without affecting thermal and mechanical properties to any great extent [9-17]. In our previous papers we described synthesis of different polyamides and poly(amide-imide)s containing heterocyclic moieties in the main chain such as hydantoin derivatives with improved solubility and thermal properties [18-26].

In this article, synthesis and characterization of novel polyamides 5a-f containing trimethylene segments by the direct polycondensation reaction of 1,3-bis(4-carboxy phenoxy) propane 3 with hydantoin $\mathbf{4 a}$ and its five derivatives; 5,5-dimethyl hydantoin $\mathbf{4 b}$, 5-ethyl-5methyl hydantoin 4c, 5,5-diethyl hydantoin 4d, 5-spiro cyclopantyl hydantoin 4e, 5-spiro cyclohexyl hydantoin $\mathbf{4 f}$ in a medium consisting of $\mathbf{N}$-methyl-2-pyrrolidone, triphenyl phosphite, calcium chloride and pyridine are described. Results showed these novel polymers with a flexible segment in the main chain have better solubility in organic solvents in compared to aromatic polyamides.

*Corresponding author. E-mail: k-faghihi@araku.ac.ir, khfaghihi@yahoo.com 
Hydantoin and hydantoin derivatives are important intermediates in the synthesis of several amino acids. In the chemical industry various hydantoin derivatives are the basis of new generation of weather proof high-temperature-stable epoxy resins. Also hydantoin constitutes an important class of heterocyclic compounds in the medicinal chemistry because many derivatives have been identified to display interesting activities against a broad range of biological targets [27].

\section{Materials}

All chemicals were purchased from Merck Chemical Company (Germany) and Aldrich Chemical Company (USA).

\section{Techniques}

${ }^{1} \mathrm{H}-\mathrm{NMR}$ spectra were recorded on a Bruker $500 \mathrm{MHz}$ instrument (Germany). Fourier transform infrared (FTIR) spectra were recorded on Galaxy series FTIR 5000 spectrophotometer (England). Spectra of solids were performed by using $\mathrm{KBr}$ pellets. Vibrational transition frequencies are reported in wavenumber $\left(\mathrm{cm}^{-1}\right)$. Band intensities are assigned as weak $(\mathrm{w})$, medium (m), shoulder ( $(\mathrm{h})$, strong (s) and broad (br). Inherent viscosities were measured by a standard procedure using a Technico Regd Trad Merk Viscometer (Germany). Thermal Gravimetric Analysis (TGA and DTG) data for polymers were taken on a Mettler TA4000 System under $\mathrm{N}_{2}$ atmosphere at a rate of $10{ }^{\circ} \mathrm{C} / \mathrm{min}$ (Germany). Differential scanning calorimetric analysis was performed on differential scanning calorimeter (Du Pont 910) at a heating rate of $10{ }^{\circ} \mathrm{C} / \mathrm{min}$ (USA). Elemental analyses were performed by the Arak Petrochemical Company, Arak, Iran. Weight-average $M_{w}$ and number-average molecular weights $M_{n}$ were determined by gel permeation chromatography (GPC) (USA). The eluents were monitored with a UV detector (JMST Systems, USA, VUV-24) at $254 \mathrm{~nm}$. Polystyrene was used as the standard.

\section{Monomer synthesis}

\section{1,3-bis(4-Carboxy phenoxy) propane 3}

Diacid 3 was prepared according to a typical procedure shown in Scheme 1. Into a $250 \mathrm{~mL}$ round bottomed flask with dropping funnel and provided with stirring bar $(4.60 \mathrm{~g}, 33.3 \mathrm{mmol})$ of 4-hydroxy benzoic acid 1 and a solution of $(2.60 \mathrm{~g}, 65.0 \mathrm{mmol})$ sodium hydroxide in $14.0 \mathrm{~mL}$ $\mathrm{H}_{2} \mathrm{O}$ were placed. The mixture well-stirred and $(3.40 \mathrm{~g}, 16.8 \mathrm{mmol})$ of 1,3-dibromo propane 2 was slowly added. The mixture was refluxed for $3.5 \mathrm{~h}$, then $(0.66 \mathrm{~g}, 16.5 \mathrm{mmol})$ of sodium hydroxide was added. After that the mixture was continuously refluxed for $2 \mathrm{~h}$, and stirred for over night at room temperature. The white precipitate was filtered and washed with $10 \mathrm{~mL}$ of methanol. The crude product was purified by dissolving in $34 \mathrm{~mL} \mathrm{H}_{2} \mathrm{O}$, reprecipitated by $3 \mathrm{M}$ $\mathrm{H}_{2} \mathrm{SO}_{4}$ solution and washed with cold water, then filtered and dried to obtain $6.32 \mathrm{~g}(60 \%)$ of white precipitate of pure 1,3-bis (4-carboxy phenoxy) propane 3 with m.p. $318-320^{\circ} \mathrm{C}$.

FT-IR (KBr): 2511-3016 (s, br), 1678 (s), 1606 (s), 1431 (s), 1303 (s), 1249 (s), 1170 (s), 1055 (m), 1514 (m), 999 (m), 848 (m), 766 (s), 542 (w), 549 (w) $\mathrm{cm}^{-1} .{ }^{1}$ H-NMR (DMSO-d ${ }_{6}$ ), TMS) $\delta: ~ 2.18-2.23(\mathrm{q}, 2 \mathrm{H}), 4.18-4.22(\mathrm{t}, 4 \mathrm{H}), 7.01-7.04(\mathrm{~d}, 4 \mathrm{H}), 7.86-7.89$ (d, 4H), 12.62 (s, br, 2H) ppm. Elemental anal. calcd for $\mathrm{C}_{17} \mathrm{H}_{16} \mathrm{O}_{6}$ : C, 64.58; H, 5.06; found: C, 64.2; H, 5.0. 


\section{Hydantoin derivatives $\mathbf{4 a - f}$}

These compounds were prepared according to a typical procedure shown in Scheme 2 [28].

Polymer synthesis

The PAs 5a-f were prepared by the following general procedure (using polymer 5a as an example). Into a $25 \mathrm{~mL}$ round-bottomed flask which was fitted with a stirring bar were placed hydantoin $4 \mathbf{a}(0.064 \mathrm{~g}, 0.64 \mathrm{mmol})$, diacid $3(0.202 \mathrm{~g}, 0.64 \mathrm{mmol})$, calcium chloride $(0.200 \mathrm{~g}$, $1.80 \mathrm{mmol})$, triphenyl phosphite $(1.68 \mathrm{~mL}, 6.00 \mathrm{mmol})$, pyridine $(0.36 \mathrm{~mL})$ and N-methyl-2pyrolidone $(1.6 \mathrm{~mL})$. The reaction mixture was gradually refluxed using an oil bath at $60{ }^{\circ} \mathrm{C}$ for $1 \mathrm{~h}, 90{ }^{\circ} \mathrm{C}$ for $2 \mathrm{~h}$, and at $130{ }^{\circ} \mathrm{C}$ for $8 \mathrm{~h}$. The reaction mixture was poured into $25 \mathrm{~mL}$ of methanol and the precipitated polymer was collected by filtration and washed thoroughly by methanol and dried at $60{ }^{\circ} \mathrm{C}$ for $12 \mathrm{~h}$ under vacuum to leave $0.208 \mathrm{~g}(86 \%)$ of yellow solid polymer 5a. The PAs 5a-f were analyzed by using FT-IR spectroscopy.

Polymer 5a. FT-IR (KBr): 2958(w), 1712(s), 1604(s), 1514(m), 1473(m), 1423(w), 1317(m), 1271(s), 1221(s), 1163(s), 1109(s), 1078(s), 985(m), 962(m), 848(m), 767(m), 744(m), 694(w) $\mathrm{cm}^{-1}$.

Polymer 5b. FT-IR (KBr): 2950(w), 1714(s), 1604(s), 1514(m), 1489(w), 1423(w), 1317(m), 1273(s), 1221(m), 1163(s), 1109(m), 1078(m), 1055(w), 958(w), 848(w), 767(m) cm ${ }^{-1}$.

Polymer 5c. FT-IR (KBr): 2962(w), 1715(s), 1610(s), 1514(m), 1489(w), 1423(w), 1317(m), 1273(s), 1221(m), 1163(s), 1110(m), 1078(m), 1055(w), 983(w), 848(w), 767(m), 707(w), $650(\mathrm{w}) \mathrm{cm}^{-1}$.

Polymer 5d. FT-IR (KBr): 2958(w), 1714(s), 1604(s), 1514(m), 1489(w), 1423(w), 1317(m), 1273(s), 1221(m), 1163(s), 1109(m), 1078(m), 1055(w), 985(w), 848(w), 767(m), 707(w), $650(\mathrm{w}) \mathrm{cm}^{-1}$.

Polymer 5e. FT-IR (KBr): 3203(w), 3057(w), 2958(w), 1714(s), 1604(s), 1514(m), 1489(m), 1423(w), 1317(m), 1273(s), 1221(m), 1163(s), 1109(s), 1078(s), 1055(m), 985(w), $848(\mathrm{~m})$, 744(m), 694(w), 650(w), 516(w) $\mathrm{cm}^{-1}$.

Polymer 5f. FT-IR (KBr): 2957(w), 2876(w), 1714(s), 1604(s), 1514(m), 1491(m), 1473(w), 1423(w), 1317(m), 1259(s), 1221(m), 1165(s), 1109(m), 1078(m), 985(w), 962(w), 848(m), 767(m), 744(m) $\mathrm{cm}^{-1}$.

\section{RESULTS AND DISCUSSION}

Monomer synthesis

1,3-bis(4-Carboxy phenoxy) propane $\mathbf{3}$ was prepared from the reaction of 4-hydroxy benzoic acid 1 with 1,3-dibromo propane 2 in the presence of $\mathrm{NaOH}$ solution. The chemical structure of diacid 3 was proved with elemental analysis, ${ }^{1} \mathrm{H}-\mathrm{NMR}$, and FT-IR spectroscopy [29].

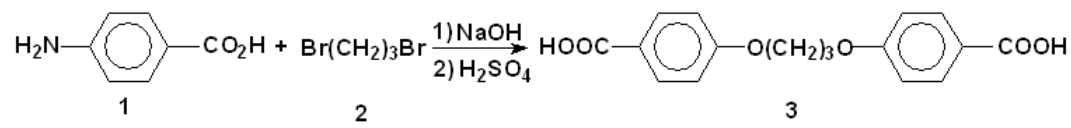

Scheme 1

Bull. Chem. Soc. Ethiop. 2010, 24(1) 
5,5-Disubstituted hydantoin derivatives were synthesized by the Bucherer-Berg method. The hydantoin compounds (4a-f) (Scheme 2) were prepared through the reaction of cyanohydrin derivatives with ammonium carbonate [28].

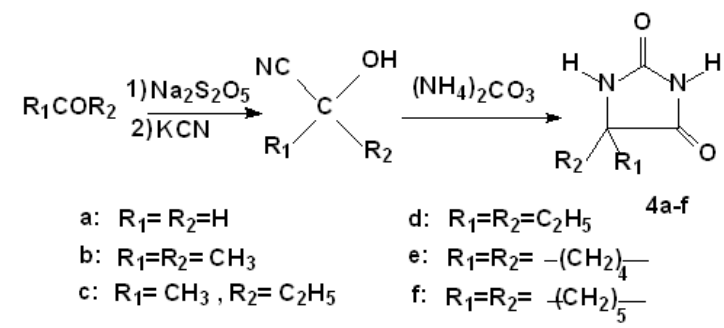

Scheme 2

Polymer synthesis

PAs 5a-f were synthesized by the direct polycondensation reaction of an equimolar mixture of diacid $\mathbf{3}$ with six aromatic diamines 5a-f in a medium consisting of N-methyl-2-pyrrolidone, triphenyl phosphite, calcium chloride and pyridine (Scheme 3). The syntheses and some physical properties of these new PAs 5a-f are given in Table 1. The entire polycondensation reaction readily proceeded in a homogeneous solution, tough and stringy precipitates formed when the viscous PAs solution was obtained in moderate to good yields.

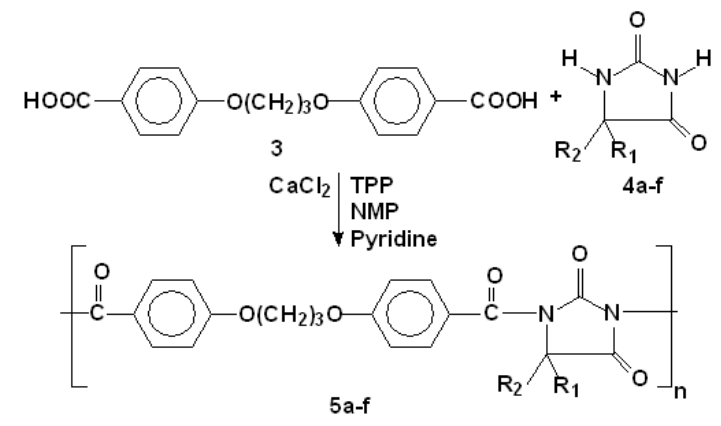

\section{Polymer characterization}

Scheme 3

The syntheses and some physical properties of PAs 5a-f are summarized in Table 1. The resulting white to yellow crystal polymers had inherent viscosities around $0.30-0.47 \mathrm{dL} / \mathrm{g}$.

Table 1. Synthesis and some physical properties of polyamide $\mathbf{5 a - f .}$

\begin{tabular}{|c|c|c|c|c|c|c|}
\hline Hydantoin & Polymer & Yield (\%) & $\eta_{\text {inh }}(\mathrm{dL} / \mathrm{g})^{\mathrm{a}}$ & $\mathrm{M}_{\mathrm{n}}\left(10^{4}\right)^{\mathrm{b}}$ & $\mathrm{M}_{\mathrm{w}}\left(10^{4}\right)^{\mathrm{b}}$ & PDI \\
\hline 4a & $\mathbf{5 a}$ & 92 & 0.47 & 2.1 & 5.8 & 2.76 \\
\hline $\mathbf{4 b}$ & $\mathbf{5 b}$ & 86 & 0.42 & 1.9 & 5.7 & 3.00 \\
\hline $\mathbf{4 c}$ & $\mathbf{5 c}$ & 85 & 0.35 & 1.4 & 4.3 & 3.07 \\
\hline $\mathbf{4 d}$ & $\mathbf{5 d}$ & 76 & 0.38 & 2.0 & 5.9 & 2.95 \\
\hline 4e & $\mathbf{5 e}$ & 89 & 0.40 & 2.2 & 4.8 & 2.18 \\
\hline 4f & $\mathbf{5 f}$ & 94 & 0.30 & 2.2 & 5.4 & 2.45 \\
\hline
\end{tabular}

${ }^{\mathrm{a}}$ Measured at a concentration of $0.5 \mathrm{~g} / \mathrm{dL}$ in DMF at $25^{\circ} \mathrm{C}$. ${ }^{\mathrm{b}}$ Measured by GPC in DMF, polystyrene was used as standard. 
These polymers were confirmed to be PAs with FT-IR spectroscopy and elemental analyses. FT-IR spectrum shows the carbonyl peaks of hydantoin moiety at $1700-1714 \mathrm{~cm}^{-1}$ and the carbonyl peaks of amide group in polymer shifted to lower frequency in comparison with diacid 4 at $1695 \mathrm{~cm}^{-1}$ and disappearance of $-\mathrm{OH}$ di-acid peak at $2500-3100 \mathrm{~cm}^{-1}$. The ${ }^{1} \mathrm{H}-\mathrm{NMR}$ spectrum of PA 5a shows two doublets between 7.01-7.04 ppm and 7.86-7.89 ppm which were assigned to the $\mathrm{H}_{\mathrm{d}}$ and $\mathrm{H}_{\mathrm{e}}$ protons of the phenyl ring. A multiplet between 2.18-2.23 ppm was assigned to the $\mathrm{H}_{\mathrm{a}}$ and a triplet between 4.1-4.2 ppm was assigned to the $\mathrm{H}_{\mathrm{c}}$ of methylene group. Also the singlet at $2.75 \mathrm{ppm}$ was assigned to the $\mathrm{H}_{\mathrm{b}}$ of hydantoin ring.

These polymers exhibited number-average molecular weights $M_{n}$ and weight-average molecular weights $\mathrm{M}_{\mathrm{w}}$ in the range of 1.4-2.2 $\times 10^{4}$ and 4.3-5.9 $\times 10^{4} \mathrm{~g} / \mathrm{mol}$, respectively, as measured by GPC, relative to polystyrene standards.

The elemental analysis of the resulting polymers is in good agreement with the calculated values for the proposed structures (Table 2).

Table 2. Elemental analysis of the resulting polyamide 5a-f.

\begin{tabular}{|c|c|c|c|c|c|}
\hline Polymer & Formula & & $\mathrm{C} \%$ & $\mathrm{H} \%$ & $\mathrm{~N} \%$ \\
\hline & $\mathrm{C}_{20} \mathrm{H}_{16} \mathrm{~N}_{2} \mathrm{O}_{6}$ & Calcd & 63.17 & 4.20 & 7.36 \\
5a & $(380.20)_{n}$ & found & 62.10 & 3.50 & 7.00 \\
\hline & $\mathrm{C}_{22} \mathrm{H}_{20} \mathrm{~N}_{2} \mathrm{O}_{6}$ & Calcd & 64.72 & 4.90 & 6.85 \\
5b & $(408.22)_{n}$ & found & 65.40 & 4.00 & 5.90 \\
\hline & $\mathrm{C}_{23} \mathrm{H}_{22} \mathrm{~N}_{2} \mathrm{O}_{6}$ & Calcd & 65.42 & 5.21 & 6.63 \\
$\mathbf{5 c}$ & $(422.23)_{\mathrm{n}}$ & found & 64.90 & 5.00 & 6.10 \\
\hline & $\mathrm{C}_{24} \mathrm{H}_{24} \mathrm{~N}_{2} \mathrm{O}_{6}$ & Calcd & 66.07 & 5.50 & 6.41 \\
5d & $(436.24)_{n}$ & found & 65.30 & 4.50 & 7.30 \\
\hline & $\mathrm{C}_{24} \mathrm{H}_{22} \mathrm{~N}_{2} \mathrm{O}_{6}$ & Calcd & 66.37 & 5.06 & 6.44 \\
$\mathbf{5 e}$ & $(434.24)_{\mathrm{n}}$ & found & 65.30 & 4.70 & 5.80 \\
\hline & $\mathrm{C}_{25} \mathrm{H}_{24} \mathrm{~N}_{2} \mathrm{O}_{6}$ & Calcd & 66.98 & 5.35 & 6.24 \\
$\mathbf{5 f}$ & $(448.25)_{\mathrm{n}}$ & found & 66.20 & 5.10 & 6.70 \\
\hline
\end{tabular}

The solubility behavior of PAs 5a-f was investigated with $0.01 \mathrm{~g}$ polymeric samples in $2 \mathrm{~mL}$ of solvent. All the polymers are soluble in organic solvents such as DMF, DMAC, DMSO, NMP, THF and acetone at room temperature and are insoluble in solvents such as chloroform, methylene chloride, methanol, ethanol and water.

\section{Thermal properties}

The thermal properties of resulting PAs 5a-f were investigated with TGA and DTG in a nitrogen atmosphere at a heating rate of $10{ }^{\circ} \mathrm{C} / \mathrm{min}^{-1}$ and the thermal data are summarized in Table 3 (Figure 1). The initial decomposition temperatures of 5 and $10 \%$ weight losses $\left(\mathrm{T}_{5}\right.$ and $\left.\mathrm{T}_{10}\right)$ and the char yield at $600{ }^{\circ} \mathrm{C}$ for them are summarized in Table 3 . These polymers exhibited good resistance to thermal decomposition, up to $325-415^{\circ} \mathrm{C}$ in nitrogen, and began to decompose gradually above that temperature. $\mathrm{T}_{5}$ for these polymers ranged from $325-415^{\circ} \mathrm{C}$ and $\mathrm{T}_{10}$ for all polymers ranged from 365 to $430{ }^{\circ} \mathrm{C}$, and the residual weight for these polymers at $600{ }^{\circ} \mathrm{C}$ ranged from 22 to $65 \%$ in nitrogen. In the DSC experiments, there is no melting endotherm in the DSC thermograms. Glass transition temperatures of these polymers were found to be in the range of $130-150{ }^{\circ} \mathrm{C}$. Also polyamide $\mathbf{5 e}$ and $\mathbf{5 f}$ containing spirocyclopantyl and spirocyclohexyl in C-5 hydantoin ring exhibited higher thermal stability compared to other PAIs 5a-d. 


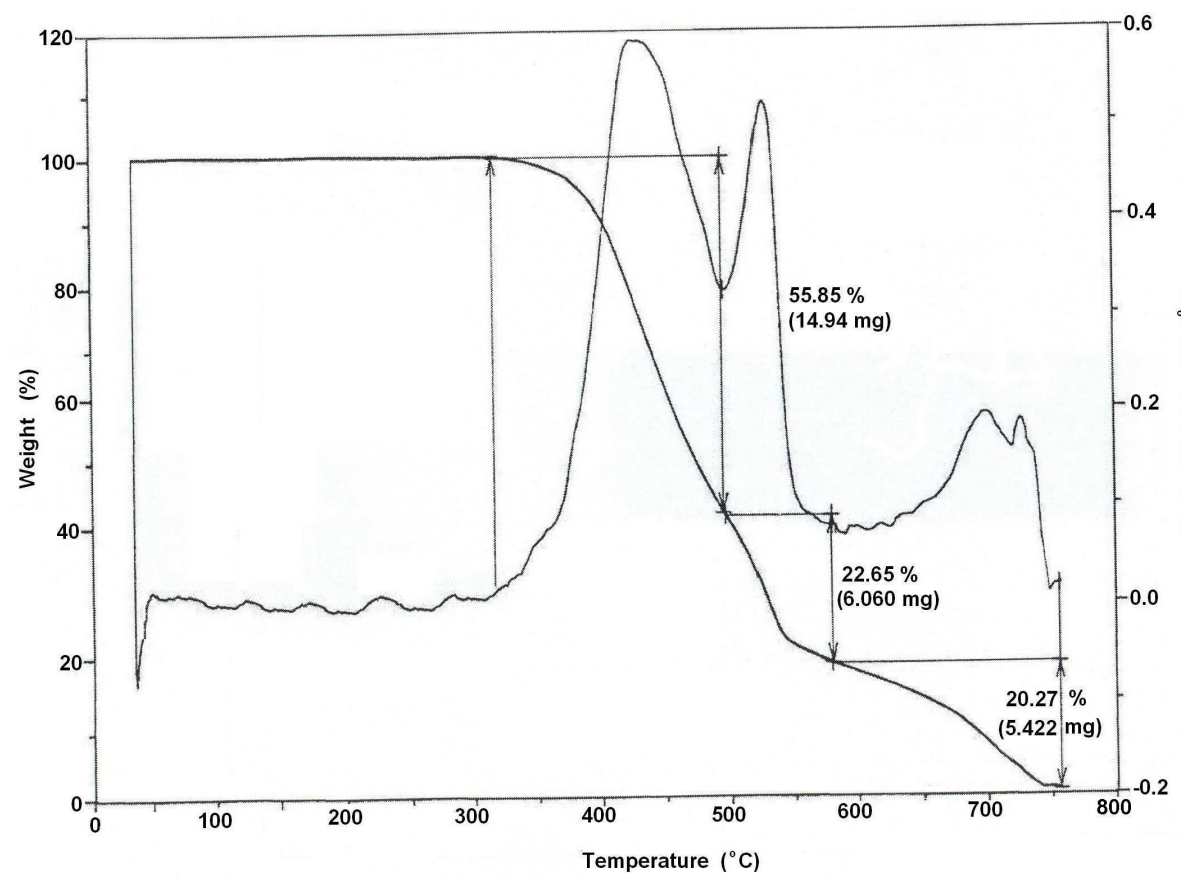

Figure 1. TGA and DTG thermograms of PA $\mathbf{5 d}$.

Table 3. Thermal behavior of polyamide 5a-f.

\begin{tabular}{|c|c|c|c|c|}
\hline Polymer & $\mathrm{Tg}^{\mathrm{a}}$ & $\mathrm{T}_{5}\left({ }^{\circ} \mathrm{C}\right)^{\mathrm{b}}$ & $\mathrm{T}_{10}\left({ }^{\circ} \mathrm{C}\right)^{\mathrm{c}}$ & Char yield $^{\mathrm{d}}(\%)$ \\
\hline $\mathbf{5 a}$ & 135 & $345-350$ & $395-400$ & 58 \\
\hline $\mathbf{5 b}$ & 140 & $325-330$ & $365-370$ & 62 \\
\hline $\mathbf{5 c}$ & 130 & $345-350$ & $410-415$ & 41 \\
\hline $\mathbf{5 d}$ & 150 & $400-405$ & $430-435$ & 22 \\
\hline $\mathbf{5 e}$ & 130 & $410-415$ & $420-425$ & 64 \\
\hline $\mathbf{5 f}$ & 145 & $415-420$ & $425-430$ & 65 \\
\hline
\end{tabular}

The glass-transition temperatures (Tg) were measured by DSC. ${ }^{\text {b,c }}$ Temperature at which $5 \%$ and $10 \%$ weight loss was recorded by TGA at heating rate of $10{ }^{\circ} \mathrm{C} / \mathrm{min}$ in $\mathrm{N}_{2}$, respectively. ${ }^{\mathrm{d}}$ Percentage weight of material left undecomposed after TGA analysis $600{ }^{\circ} \mathrm{C}$.

\section{CONCLUSIONS}

This work involved the syntheses of several new PAs 5a-f through direct polycondensation reaction of diacid 3 with six hydantoin derivatives $\mathbf{4 a - f}$ by using triphenyl phosphite, NMP, calcium chloride and pyridine as condensing agents. These new PAs were soluble in various organic solvents and had moderate thermal stability. The presence of trimethylene as a flexible segment into the backbone increased the solubility of these polymers in comparison to aromatic polyamides. These properties could make these PAs attractive for practical applications, such as processable high-performance engineering plastics. 
New polyamides based on 1,3-bis(4-carboxy phenoxy) propane and hydantoin derivatives

\section{REFERENCES}

1. Cassidy, P.E. Thermally Stable Polymers, Synthesis and Properties, Dekker: New York; 1980.

2. Morgan, P.W. Chemtech. 1979, 9, 316.

3. Park, K.P.; Kakimoto, M.A.; Imai, Y. J. Polym. Sci. Part A: Polym. Chem. 1995, 33, 1031.

4. Yang, C.P.; Hsiao, S.H.; Yang, C.C. J. Polym. Sci. Part A: Polym. Chem. 1997, 35, 2147.

5. Hendrick, J.L.; Twieg, R. Macromol. 1992, 25, 2021.

6. Choi, K.H.; Jung, J.C. Macromol. Mater. Eng. 2004, 289, 737.

7. Yang, C.P.; Hsiao, S.H.; Chung, C.L. Polym. Int. 2005, 54, 716.

8. Hsiao, S.H.; Yang, C.P.; Huang, S.C. J. Polym. Sci. Part A: Polym. Chem. 2004, 42, 2377.

9. Wang, X.L.; Li, Y.F.; Gong, C.L.; Ma, T.; Yang, F.C. J. Fluorine Chem. 2008, 129, 56.

10. Li, N.; Cui, Z.; Zhang, S.; Xing, W. Polym. 2007, 48, 7255.

11. Hamciuc, E.; Hamciuc, C.; Cazacu, M. Eur. Polym. J. 2007, 43, 4739.

12. Zhang, Q.; Li, S.; Li, W.; Zhang, S. Polym. 2007, 48, 624.

13. Zhao, X.; Li, Y.F.; Zhang, S.J.; Shao, Y.; Wang, X.L. Polym. 2007, 48, 5241.

14. Zhu, Y.; Zhao, P.; Cai, X.; Meng, W.D.; Qing, F.L. Polym. 2007, 48, 3116.

15. Mehdipour Ataei, S.; Bahri Laleh, N.; Amirshaghaghi, A. Polym. Degrad. Stability. 2006, 91, 2622.

16. Lee, S.B.; Shin, G.J.; Chi, J.H.; Zin, W.C.; Jung, J.C.; Hahm, S.G.; Ree, M.; Chang, T. Polym. 2006, 47, 6606.

17. Mehdipour Ataei, S.; Arabi, H.; Bahri Laleh, N. Eur. Polym. J. 2006, 42, 2343.

18. Faghihi, Kh.; Hajibeygi, M. Eur. Polym. J. 2003, 39, 2307.

19. Faghihi, Kh.; Zamani, Kh.; Mirsamie, A. Mallakpour, S.E. J. Appl. Polym. Sci. 2004, 91, 516.

20. Faghihi, Kh.; Zamani, Kh.; Mirsamie, A. Mallakpour, S.E. Polym. Int. 2004, 53, 126.

21. Faghihi, Kh.; Hajibeygi, M. Macromol. Res. 2005, 13, 14.

22. Faghihi, Kh.; Naghavi, H. J. Appl. Polym. Sci. 2005, 96, 1776.

23. Faghihi, Kh. Polym. J. 2005, 37, 449.

24. Faghihi, Kh. J. Appl. Polym. Sci. 2006, 102, 5062.

25. Faghihi, Kh.; Mozaffari, Z. J. Appl. Polym. Sci. 2008, 108, 1152.

26. Faghihi, Kh.; Naghavi, H. J. Appl. Polym. Sci. 2008, 108, 1136.

27. Lamothe, M.; Lannuzel, M.; Perez, M. J. Comb. Chem. 2002, 4, 73.

28. Faghihi, Kh.; Zamani, Kh.; Mirsamie, A.; Sangi, R. Eur. Polym. J. 2003, 39, 247.

29. Nasr Isfahani, H.; Faghihi, Kh.; Valikhani, N. J. Appl. Polym. Sci. 2009, 111, 1769. 